\title{
Imaging ROS signaling in cells and animals
}

\author{
Xianhua Wang • Huaqiang Fang • Zhanglong Huang • \\ Wei Shang • Tingting Hou • Aiwu Cheng • Heping Cheng
}

Received: 7 April 2013 /Revised: 8 June 2013 / Accepted: 17 June 2013 / Published online: 20 July 2013

(C) The Author(s) 2013. This article is published with open access at Springerlink.com

\begin{abstract}
Reactive oxygen species (ROS) act as essential cellular messengers, redox regulators, and, when in excess, oxidative stressors that are widely implicated in pathologies of cancer and cardiovascular and neurodegenerative diseases. Understanding such complexity of the ROS signaling is critically hinged on the ability to visualize and quantify local, compartmental, and global ROS dynamics at high selectivity, sensitivity, and spatiotemporal resolution. The past decade has witnessed significant progress in ROS imaging at levels of intact cells, whole organs or tissues, and even live organisms. In particular, major advances include the development of novel synthetic or genetically encoded fluorescent protein-based ROS indicators, the use of protein indicator-expressing animal models, and the advent of in vivo imaging technology. Innovative ROS imaging has led to important discoveries in ROS signaling-for example, mitochondrial superoxide flashes as elemental ROS signaling events and hydrogen peroxide transients for wound healing. This review aims at providing an update of the current status in ROS imaging, while identifying areas of insufficient knowledge and highlighting emerging research directions.
\end{abstract}

Keywords Reactive oxygen species (ROS) · Mitochondria · ROS signaling $\cdot$ ROS indicators $\cdot$ In vivo imaging

X. Wang $\cdot$ H. Fang $\cdot$ Z. Huang $\cdot$ W. Shang $\cdot$ T. Hou $\cdot$ H. Cheng $(\bowtie)$ State Key Laboratory of Biomembrane and Membrane Biotechnology, Institute of Molecular Medicine, Peking-Tsinghua Center for Life Sciences, Beijing Key Laboratory of Cardiometabolic Molecular Medicine, Peking University, Beijing 100871, China e-mail: chengp@pku.edu.cn

A. Cheng

Laboratory of Neurosciences, National Institute on Aging

Intramural Research Program, Baltimore, MD 21224, USA

\section{Introduction}

Reactive oxygen species (ROS) are oxygen metabolites that are highly active in terms of oxidative modifications of cellular macromolecules including proteins, lipids, and polynucleotides. Superoxide radical $\left(\mathrm{O}_{2}{ }^{-}\right)$is usually the primal ROS species produced and is subsequently converted into hydrogen peroxide $\left(\mathrm{H}_{2} \mathrm{O}_{2}\right)$ through spontaneous or superoxide dismutase (SOD)-catalyzed dismutation. And reaction of $\mathrm{O}_{2}{ }^{-}$and nitric oxide $(\cdot \mathrm{NO})$ generates peroxynitrite $\left(\mathrm{ONOO}^{-}\right)$, a $\mathrm{ROS}$ and reactive nitrogen species (RNS) species. Of all cellular ROS sources, electron leakage from the mitochondrial electron transfer chain (ETC) to molecular oxygen generates a steady flux of $\mathrm{O}_{2}{ }^{-}$and thus constitutes the major site of cellular ROS production $[1,2]$. Other enzymes, including NADPH oxidases, lipoxygenase and cyclooxygenase, cytochrome p450s, and xanthine oxidase, also participate in ROS generation [3].

The cellular redox homeostasis is set by a delicate balance between ROS production and the antioxidant system. The ROS-scavenging enzymes include SODs, which convert $\mathrm{O}_{2}{ }^{--}$to $\mathrm{H}_{2} \mathrm{O}_{2}$, and catalases, which convert $\mathrm{H}_{2} \mathrm{O}_{2}$ to water. The antioxidant system consists of glutathione, peroxiredoxin, thioredoxin, and NADPH. Collectively, they form an antioxidant pool, while a third category of enzymes such as glutathione peroxidase and thioredoxin reductase catalyze the interconversion and equilibrium among the reduced/oxidized species of different reductants $[4,5]$.

When ROS are produced excessively or endogenous antioxidant capacity is diminished, indiscriminate oxidation elicits harmful effects, resulting in "oxidative stress". Mounting evidence has established strong links between oxidative stress and a wide variety of pathologies including malignant diseases, diabetes mellitus, atherosclerosis, ischemia-reperfusion injury, and chronic inflammatory processes as well as many neurodegenerative diseases [3, 6-14]. Moreover, the oxidative stress theory of aging states that systematic accumulation of oxidative damage from multiple ROS 
sources constitutes the core process that drives the biological clock of aging $[15,16]$. Nevertheless, homeostatic ROS are required to maintain a redox environment optimal to biochemical activities of the cell. It has been shown that acute application of SOD mimetics to cardiomyocytes halves the rate of occurrence of spontaneous $\mathrm{Ca}^{2+}$ sparks [17] and decreases action potential-elicited $\mathrm{Ca}^{2+}$ transients and contraction [18]. "Reductive stress", a state with too little ROS production and/or too strong antioxidant reactivity, can also lead to pathology. For instance, cardiac-specific expression of human alphaB-crystallin autosomal-dominant mutant hR120GCryAB led to reductive stress causing cardiomyopathy through inducing protein aggregation $[19,20]$.

As an exciting paradigm-shifting development, ROS emerge as powerful, ubiquitous, and indispensable cellular messengers, adding to the repertoire of only a handful of second messengers that we know $\left(\mathrm{Ca}^{2+}, \mathrm{cAMP}, \mathrm{IP}_{3}\right.$, and arachidonic acid). The specific ROS targets range from ionic channels and transporters, to kinases and phosphatase, and to transcription factors, and the list continues to grow and permeate throughout pivotal pathways in differentiation and organogenesis [21], cell fate regulation [22, 23], stress response [24], and wound healing [25, 26]. However, ROS signaling is notoriously complex. As a rule of thumb, the ROS effects are multiphasic and bidirectional, depending on the species of oxidants, their concentrations, history of exposure, and cellular context. The proven failure of antioxidant therapies despite decades of industrious efforts [27-30] serves us a humbling lesson on how much we still do not know about ROS signaling. Understanding the cell logic and principles of ROS signaling and developing efficient and specific antioxidant therapies to constrain ROS damages would both hinge on precise and quantitative knowledge of intracellular ROS dynamics, concentrations, compartments, and modes of action.

A few harbingers show us the new horizons in ROS research. First, the trend of ROS investigation moving from cell-free preparations to intact cells and even in living animals; second, the development of a set of novel fluorescent protein-based ROS indicators and protein indicator-expressing transgenic animal models, enhanced with cell type and subcellular compartmenttargeting ability; and third, the visualization of exquisite spatiotemporal architecture of intracellular ROS dynamics by time-lapse imaging in intact cells or in vivo imaging in transgenic animal models. In this short review, we summarize these recent advances in fluorescent ROS imaging in cells and animals with emphasis on novel indicators, genetic animal models, and in vivo imaging technology. Emerging concepts on local ROS signaling will also be discussed. Please see references [31-34] for recent reviews on related topics.
ROS measurement with small-molecule fluorescent probes

Depending on ROS species and cellular environments, lifetime of a ROS molecule in biological systems varies from nanoseconds to seconds. So what is required for a fluorescent ROS indicator is that it should compete with the antioxidants for ROS and produce fluorescently altered products for visualization and quantification [35]. For an "ideal" ROS indicator, the criteria include selectivity for specific ROS species, fast and reversible kinetics, high signal-tobackground contrast, and superb signal-to-noise properties as well as ease with intracellular loading and proper subcellular compartmentalization. It is also desirable to be excitable at a visible wavelength, be resistant to photobleaching, and display no toxicity in general and phototoxicity in particular. Currently available fluorescent ROS indicators fall in two categories, synthetic small-molecule dyes and genetically encoded fluorescent protein-based probes. As will be discussed in the following, major limitations in ROS measurements are related to selectivity, kinetics, and ability for quantitative calibration.

Of the small-molecule fluorescent ROS probes, $2^{\prime}-7^{\prime}$ dichlorodihydrofluorescein (DCFH), dihydroethidium (DHE), and mitochondrial-targeted DHE (mitoSOX) are the most popular ones. The diacetate form of DCFH (DCFH-DA) is a cell-permeable form that allows ester loading of the dye, resulting in intracellular accumulation of the nonfluorescent DCFH. In the presence of $\mathrm{H}_{2} \mathrm{O}_{2}$ and other oxidants, two-electron oxidation of DCFH results in the formation of a fluorescent product, 2'-7'-dichlorofluorescein (DCF), which can be monitored by fluorescence microscopy and flow cytometry $[33,36]$. However, severe limitations and potential artifacts are confounding the DCF measurement of ROS. Apart from its relative nonselectivity to ROS species and oxidants, DCFH oxidation can also be catalyzed by cytochrome $\mathrm{c}$ and heme peroxidases. Worse, the oneelectron oxidization product or DCF radical can react with oxygen to produce $\mathrm{O}_{2}{ }^{--}$and subsequently $\mathrm{H}_{2} \mathrm{O}_{2}$, thus artificially generating the very ROS that it is attempting to quantify. Cautions should also be taken to minimize light exposure because DCFH is both susceptible to photo-oxidation (increasing DCF fluorescence) and to photobleaching (loss of DCF fluorescence). Kinetically, it is difficult for DCFH to track small and rapid ROS transients because DCFH oxidation is irreversible in the intracellular milieu, and the slope of DCF fluorescence rise ( $\mathrm{dF} / \mathrm{dt}$ ), instead of fluorescence intensity (F) per se, is often used to measure the level of ROS. After subtraction of the rising basal fluorescence $\left(F_{\text {base }}\right)$, local $d\left(F-F_{\text {base }}\right) / \mathrm{dt}$ has also been used to reflect approximately brief ROS transient [37]. This procedure, however, could be complicated because oxidized DCF becomes membrane-permeable [38]. As to its subcellular compartmentalization, DCFH may be enriched in either the cytosol 
or the organelle mitochondria, depending on loading and experimental conditions [39].

DHE is widely used as a small-molecule fluorescent ROS probe specific for $\mathrm{O}_{2}{ }^{--}$[40]. The reaction between $\mathrm{O}_{2}{ }^{-}$and DHE generates a highly specific red fluorescent product, 2hydroxyethidium $(2-\mathrm{OH}-\mathrm{E}(+))$, shifting its excitation and emission peaks from 350 and 400 to 518 and $605 \mathrm{~nm}$, respectively [41-43]. mitoSOX, a DHE derivative with addition of a positively charged triphenylphosphonium group (TPP+), is highly enriched in the mitochondria [44, 45], and the binding of oxidized mitoSOX to mtDNA greatly enhances its fluorescence [43]. The chemical reactivity of mitoSOX with $\mathrm{O}_{2}{ }^{--}$is similar to the reactivity of DHE with $\mathrm{O}_{2}{ }^{--}$, and the particular product 2-OH-E $(+)$is unique to $\mathrm{O}_{2}{ }^{--}$ since several studies have confirmed that $2-\mathrm{OH}-\mathrm{E}(+)$ is the only product in the presence of $\mathrm{O}_{2}{ }^{--}$generated by the xanthine-xanthine oxidase- $\mathrm{O}_{2}$ system [46-48].

In intact cells, however, the DHE detection of $\mathrm{O}_{2}{ }^{-{ }^{-}}$is still interfered by a prominent reaction: two-electron oxidation of DHE by oxidants other than $\mathrm{O}_{2}{ }^{--}$produces ethidium cation $(\mathrm{E}+)$, another red fluorescent product that is bound to nuclear DNA and often present at a much higher concentration [43]. It has recently been suggested that selective detection of 2$\mathrm{OH}-\mathrm{E}+$ is possible by excitation at $396 \mathrm{~nm}$ because an excitation band between 350 and $400 \mathrm{~nm}$ is present for 2$\mathrm{OH}-\mathrm{E}+$ but not $\mathrm{E}+[49]$. However, other studies have reported that $\mathrm{E}+$ can still significantly contribute to the fluorescence intensity even at $396 \mathrm{~nm}$ excitation because of high levels of $\mathrm{E}+$ involved [50]. These indicators are also lightsensitive and prone to auto-oxidation [35, 43], further constraining and complicating design and data interpretation in time-lapse experiments. Additionally, it has been shown that mitoSOX at high concentration significantly impairs mitochondrial function [49].

Several other useful small-molecule fluorescent ROS probes have been developed. Particularly, dihydrorhodamine 123 (DHR123) is a nonfluorescent agent that scavenges the $\mathrm{OH}$. generated from $\mathrm{H}_{2} \mathrm{O}_{2}$ in an iron-dependent Fenton reaction and is thereby converted into the fluorescent rhodamine 123 [51]. DHR123 reacts also with $\mathrm{NO}_{2}$ and hypochlorous acid but is unreactive to $\mathrm{O}_{2}{ }^{--}$or $\mathrm{H}_{2} \mathrm{O}_{2}$ in the absence of catalyst [34, 52-54]. A family of boronate-based indicators (e.g., peroxysensor family) has also been introduced for targeting to the cytosol or the mitochondria [55-57]. Boronate masks the fluorophore; but, upon exposure to $\mathrm{H}_{2} \mathrm{O}_{2}$, it undergoes a nucleophilic attack and its removal unmasks the fluorescence emission. However, the boronate-based indicators are promiscuous as they also react stoichiometrically with $\mathrm{ONOO}^{-}$, yielding phenols and permitting light emission [58, 59].

HKGreen-3, a rhodol-based fluorescent probe, is recently developed by Peng et al. and shows high sensitivity and selectivity for peroxynitrite in both chemical and biological systems [60]. HKOCl-1 is a BODIPY-based fluorescent probe for detecting hypochlorous acid with high specificity [61]. 4Amino-5-methylamino-2', $7^{\prime}$-difluorofluorescein (DAF-FM) is of popularity for measuring NO due to its high sensitivity, $\mathrm{pH}$ stability, and relative resistance to photobleaching. Since the detection relies on conversion of the parent compound into a fluorescent triazole, the presence of oxidants/antioxidants and reaction with other molecules would affect this fluorescence detection [62]. Amplex UltraRed is a fluorogenic substrate for horseradish peroxidase that reacts with $\mathrm{H}_{2} \mathrm{O}_{2}$ in a 1:1 stoichiometric ratio to produce the fluorescent product resorufin with long-wavelength spectra (excitation/emission maxima, $\sim 563 / 587 \mathrm{~nm}$ ) [31]. In a recent study, Amplex UltraRed and DAF-FM have been successfully used for in vivo measurement of extracellularly released $\mathrm{H}_{2} \mathrm{O}_{2}$ and $\mathrm{NO}$ of superficial lumbar spinal cord of anesthetized mice, respectively [63].

The caveat from above considerations is that ROS measurement with small-molecule fluorescent probes is not as straightforward as it seems to be. Proper experimental design, careful choice of loading and light illumination parameters, stringent control of experimental conditions, and judicious interpretation of experimental data should all be exercised. Whenever possible, cross-confirmation with multiple independent approaches is highly recommended. Evidently, developing small-molecule fluorescent ROS probes suitable for faithful measurement of ROS dynamics remains a huge challenge to the ROS research field.

\section{ROS measurement with fluorescent protein-based indicators}

Over the last decade, fluorescent protein-based ROS indicators have entered the arsenal for ROS measurement. While protein chemistry introduces a higher level of complexity as compared to the small-molecule chemistry, it at the same time offers tremendous opportunities for rational design (e.g., redox oxidation-sensitive green fluorescent proteins (roGFPs) for redox potential measurement and HyPer for $\mathrm{H}_{2} \mathrm{O}_{2}$ measurement) [64-66] as well as serendipitous discoveries (e.g., mt-circularly permutated yellow fluorescent protein (cpYFP) for mitochondrial superoxide flashes) [67]. While selectivity is generally improved, reversibility could also be achieved by exploiting the endogenous antioxidant system or new protein chemistry. Another distinct advantage is that these genetically encoded indicators can be specifically targeted to different type of cells using cell typespecific promoters or to different cellular compartments or microdomains by $\mathrm{N}$ - or $\mathrm{C}$-terminal fusion with a specific targeting sequence $[68,69]$. ROS indicator-expressing transgenic animals have been generated [67, 70-73], allowing for imaging ROS ex vivo and in vivo. However, the fluorescent protein indicators have also their own set of limitations. 
Particularly, $\mathrm{pH}$ sensitivity is common to most of currently used protein-based ROS indicators, due to reversible fluorescencequenching protonation of the chromophore at $\mathrm{p} K_{\mathrm{a}}$ close to physiological $\mathrm{pH}$. As such, $\mathrm{pH}$ changes in the cytosol or other specific compartments, if not judiciously controlled, could lead to erroneous observation and misinterpretation.

Imaging mitochondrial superoxide flashes with cpYFP

Among all ROS sources, mitochondrial ETC is the major site of cellular ROS production. The ETC consists of intermolecular and intramolecular pathways of increasing redox potential $\left(E_{h}\right)$, from $-320 \mathrm{mV}$ at the entry point of complex I to $+390 \mathrm{mV}$ at the terminal point of complex IV. However, with its $E_{h}=-160 \mathrm{mV}, \mathrm{O}_{2}$ also snaps up $0.15-2 \%$ of the respiratory chain electrons, one at a time, at places prior to complex IV; and one-electron reduction of $\mathrm{O}_{2}$ forms $\mathrm{O}_{2}{ }^{-}[1,2]$, the primal ROS. This constitutive mode of mitochondrial ROS production plays an important role in setting the ROS and redox homeostasis of the cell.

While studying mitochondrial $\mathrm{Ca}^{2+}$ signaling with a genetically encoded mitochondrial-targeted $\mathrm{Ca}^{2+}$ indicator, pericam [74], we serendipitously found that the fluorescent moiety of pericam, cpYFP, can reversibly detect superoxide with high selectivity and sensitivity [67]. Extensive in vitro characterization indicates that, when excited at $488 \mathrm{~nm}$, cpYFP emission displays a several fold increase in response to superoxide generated by the xanthine-xanthine oxidase$\mathrm{O}_{2}$ system, but is insensitive to many other oxidants and metabolites, including $\mathrm{H}_{2} \mathrm{O}_{2}$, peroxynitrite, $\mathrm{Ca}^{2+}$, ATP, $\mathrm{ADP}, \mathrm{NAD}(\mathrm{P})^{+}$, and $\mathrm{NAD}(\mathrm{P}) \mathrm{H}$. It is also insensitive to $E_{h}$ varying between -319 and $-7.5 \mathrm{mV}$ (controlled by mix of oxidized and reduced DTT in different proportions), while displays a $\mathrm{pH}$ sensitivity with a $\mathrm{p} K_{\mathrm{a}} \sim 8.5$ [67]. The reversibility of cpYFP has been evidenced by the fact that SOD added after superoxide formation reverses the cpYFP signal in vitro. In addition, mitochondrial-targeted cpYFP (mtcpYFP) acts as a ratiometric indicator because its signal at $405 \mathrm{~nm}$ excitation is essentially ROS-independent, allowing for the use of the $F_{488} / F_{405}$ ratio as the readout.

Using mt-cpYFP, we have uncovered a new mode of mitochondrial ROS production-“superoxide flash". Superoxide flashes are sudden, brief, and bursting superoxideproducing events in single mitochondria. In intact cells, spontaneous flashes occur at a low rate in a stochastic manner [67], but their frequency can be regulated over a broad dynamic range. To date, superoxide flashes are universally found in all cell types examined, including cardiomyocytes, skeletal muscle cells, neurons, glials, fibroblasts, and several types of cancer cells [23, 67, 70, 75-82]. They are also highly conserved in species ranging from mammals (mouse, rat, and human) and to Caenorhabditis elegans (unpublished data). Ex vivo and in vivo imaging in transgenic mouse models with cardiac-specific or pan-tissue mt-cpYFP expression have allowed for detection of superoxide flashes in beating hearts under Langendorff perfusion [67] and in gastrocnemius muscle and sciatic nerve of living mice under anesthesia (Fig. 1) [70, 71]. In addition, superoxide flashes of similar characteristics are active in freshly isolated, respiratory mitochondria [83], indicating that single mitochondria contain the full machinery for the genesis of superoxide flashes. Notably, the rate of flash occurrence varies depending on species, tissue and cell types, metabolic states, the presence of stressors, and disease conditions; the amplitude and duration of the flashes, however, appear to be stereotypical at multiple levels, from isolated mitochondria, to intact or plasma membrane-permeabilized cells, to whole tissues or organs, and to living animals.

The superoxide origin of the mitochondrial flashes has stirred some hot debates. Sweetlove et al. reported similar phenomenon in Arabidopsis mitochondria, but interpreted its nature as transient alkalization of the mitochondrial matrix [84, 85]. Recently, we and others have systematically examined the respective contributions of $\mathrm{ROS}$ and $\mathrm{pH}$ to a flash and concluded that ROS burst is the dominant signal while $\mathrm{pH}$ change, if any, has only a minor contribution [83]. In experiments combining the protein and small-molecule ROS indicators, it has been shown that mitoSOX, which is $\mathrm{pH}$ insensitive, reports a concomitant stepwise increase during a mt-cpYFP flash $[78,83,86]$. Furthermore, owing to its
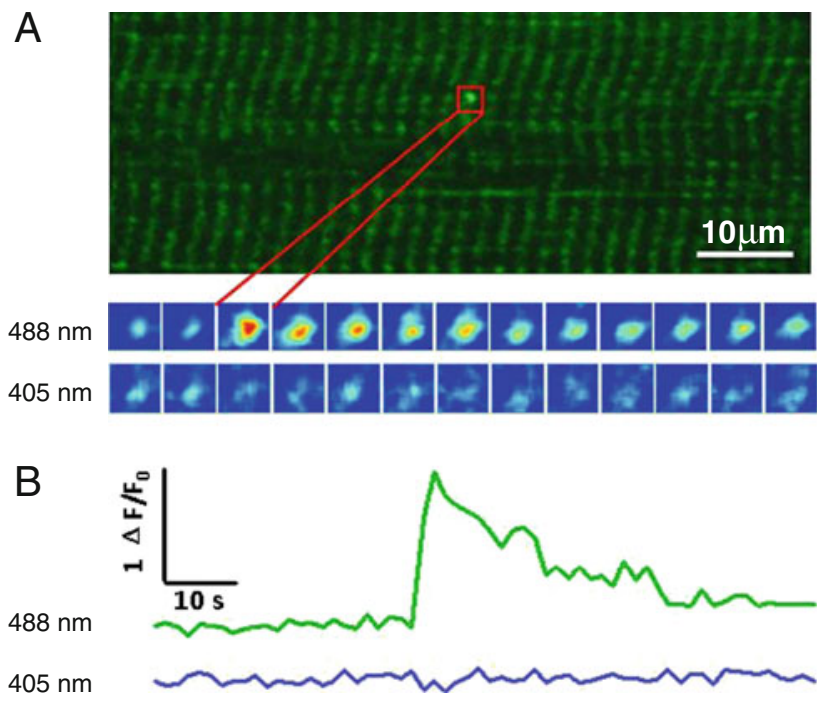

Fig. 1 In vivo detection of mitochondrial superoxide flashes in skeletal muscle. An upright confocal microscope was used to image the hindlimb skeletal muscle in $m t-c p Y F P$ transgenic mouse under anesthesia. a Superoxide flash in mouse gastrocnemius. Upper panel $x-y$ view of mitochondria at $488 \mathrm{~nm}$ excitation. The striated pattern reflects that double-row arrays of mitochondria locate at $\mathrm{Z}$ line regions of sarcomeres. Bottom panel enlarged views of this punctiform superoxide flash in the boxed region at 3-s intervals, with dual wavelength excitation at 488 and $405 \mathrm{~nm}$. b Time course of the superoxide flash in a. Modified from Fang et al. [71] 
reversibility, mt-cpYFP is able to track the time course of flashes with the briefest duration of only $\sim 1$ to $2 \mathrm{~s}$ [80].

Differing from constitutive mitochondrial ROS production, the genesis of superoxide flashes involve different but overlapping molecular mechanisms. The flash ignition is tightly coupled to transient opening of mitochondrial permeability transition pore (mPTP), evidenced by sudden dissipation of mitochondrial membrane potential and partial and irreversible loss of fluorescent solutes (MW, 752-980 Da) preloaded to the matrix $[67,75]$. The involvement of MPTP is also supported by the fact that the flash production is partially sensitive to pharmacological inhibition or molecular knockdown of cyclophilin $\mathrm{D}$, consistent with a regulatory, but dispensable, role of this protein in MPTP activity [87-90]. Another prominent property of the superoxide flashes is their dependence on functionally intact ETC. The flash production is abolished by disruption of the ETC at any possible site, complex I through $\mathrm{V}$, in a manner distinctly different from ETC regulation of constitutive ROS production. For instance, antimycin A, an inhibitor-targeting complex III abolishes the bursting quantal ROS production in the form of the flashes [67] while stimulating continuous ROS production [1,91, 92]. That inhibition of complex $\mathrm{V}$ also suppresses the flash production is consistent with an intimate relationship recently suggested for the ATP synthase and MPTP [93, 94].

By in situ, ex vivo, and in vivo ROS imaging, we and others have shown that superoxide flashes represent not only a digital readout of mitochondrial metabolic status but also a novel biomarker of mitochondrial stress. The rate of skeletal muscle superoxide flashes in live anesthetized mice increases after intraperitoneal injection of glucose or insulin, indicating that superoxide flashes are coupled to whole-body dietary glucose metabolism [70]. In isolated skeletal muscle cells with electroporation-mediated transient mt-cpYFP expression, superoxide flashes occur at a markedly elevated frequency and display a similar though less profound response to glucose plus pyruvate stimulation, in the absence of insulin and other whole-body factors [78]. A further elevated superoxide flash activity is observed in skeletal muscle of RyR1 $1^{\mathrm{Y} 522 \mathrm{~S} / \mathrm{WT}} \mathrm{ma}-$ lignant hyperthermia mice which exhibit marked temperaturedependent increases in ROS and RNS generation [76]. Thus, imaging superoxide flashes in vivo exemplifies how both the integrative whole-body metabolic response and the mechanistic single-mitochondrion behavior can be investigated in one single experiment.

Investigation of superoxide flash production in mice deficient of SOD2 has revealed that superoxide flashes negatively regulate neural progenitor proliferation and cerebral cortical development through modulating activation of ERK [23]. Remarkably, a reversible 20-fold increase of superoxide flashes occurs in response to hyperosmotic stress, due to the synergistic effect mitochondrial $\mathrm{Ca}^{2+}$ uniport, and basal ROS elevation. The high activity of superoxide flashes, in turn, contributes to activating JNK and p38, essential signals for adaptive cell survival responses [81]. In cultured cardiomyocytes, a flurry of superoxide flash activity occurs in a 5-10 min window after reoxygenation from hypoxia or anoxia $[67,95]$. In the pathology of Huntington disease, the elevated flash activity induced by elevated mitochondrial $\mathrm{Ca}^{2+}$ signaling acts to exacerbate mtDNA damage [82]. Likewise, superoxide flashes act as early mitochondrial signals mediating the apoptotic response during oxidative stress in HeLa cells [79].

Collectively, these recent advances indicate that superoxide flashes offer a rare window through which we can glimpse into the whole-body metabolic response at the single-mitochondrion level, and gauge a wide variety of stresses converging to the mitochondria. To our knowledge, many types of cpYFP transgenic organisms, from mice, zebrafish, C. elegans, Drosophila melanogaster, and yeast, have been generated or are currently being created to address multidisciplinary questions in broad settings. We are eager to see what these new models and approaches can teach us about ROS signaling in biology and diseases.

\section{Imaging $\mathrm{H}_{2} \mathrm{O}_{2}$ with HyPer}

HyPer is a ratiometric fluorescent indicator of $\mathrm{H}_{2} \mathrm{O}_{2}$ in which cpYFP is inserted into the regulatory domain of an Escherichia coli peroxide sensor OxyR [66]. Naturally used by the bacterium to trigger transcriptional response to oxidative stress, OxyR contains an $\mathrm{H}_{2} \mathrm{O}_{2}$-sensitive regulatory domain and a DNA-binding domain, and, upon oxidation by $\mathrm{H}_{2} \mathrm{O}_{2}$, intramolecular disulfide bond forms between two cysteine residues (Cys199 and Cys 208) and the resultant conformational change shifts the excitation maximum of the attached cpYFP from 420 to $500 \mathrm{~nm}$ (emission maximum at $516 \mathrm{~nm}$ ) [66]. HyPer is able to detect nanomolar $\mathrm{H}_{2} \mathrm{O}_{2}$ in vitro and, when expressed in cells, responds to micromolar $\mathrm{H}_{2} \mathrm{O}_{2}$ added externally [66] or changes of intracellular $\mathrm{H}_{2} \mathrm{O}_{2}$ upon growth factor stimulation $[66,96]$. In an elegant study, Niethammer et al. have exploited HyPer expressed in transgenic zebrafish larvae to visualize a regional, graded, and transient $\mathrm{H}_{2} \mathrm{O}_{2}$ signal produced by dual oxidase (Duox) in response to tail fin injury. Functionally, this Duox-elicited $\mathrm{H}_{2} \mathrm{O}_{2}$ signal is required for rapid recruitment of leukocytes in the process of wound healing [25].

A series of HyPer mutants have been developed in order to improve its dynamic range and reaction kinetics for $\mathrm{H}_{2} \mathrm{O}_{2}$ detection. In particular, HyPer-2, an A406V single-point mutant of HyPer, exhibits twice-expanded dynamic range, but the response to $\mathrm{H}_{2} \mathrm{O}_{2}$ is much slower, doubling both halfoxidation and half-reduction from $\sim 6$ and $\sim 200 \mathrm{~s}$ for HyPer to $\sim 13$ and $\sim 400$ s for HyPer-2, respectively [97]. Recently, a H34Y mutant of HyPer, HyPer-3, was developed, which shows expanded dynamic range compared to HyPer and 
faster oxidation-reduction kinetics compared to HyPer-2 [72]. Notably, in HyPer-3 transgenic zebrafish, similar $\mathrm{H}_{2} \mathrm{O}_{2}$ gradients along the fish tail regions were observed upon wounding; however, HyPer-3 showed a higher fluorescence ratio (F500/F420) [72] than what reported by HyPer [25] demonstrating its advantage for $\mathrm{H}_{2} \mathrm{O}_{2}$ detection.

Both HyPer and HyPer-3 are applicable for fluorescence lifetime imaging microscopy (FLIM) [72]. Instead of measuring the fluorescence intensity, the physical parameter measured in FLIM is the time constant $(\tau)$ of the excited fluorophore returning to its basal states and, in this case, the change in $\tau$ is quantified to reflect the redox state of the ROS indicator and hence the ROS level. Because $\tau$ is independent of indicator concentration, FLIM measurement is essentially insensitive to indicator expression level, non-uniform distribution, and partial photobleaching. It is also advantageous for quantifying signals at different depths in a biological tissue because $\tau$ is less interfered by light scattering and reabsorption (inner filtering). Moreover, FLIM generates absolute quantitative readouts while requiring only a single-wavelength excitation, provided that the indicator is calibrated in situ (e.g., in permeablized cells) or in vitro under conditions closely resembling intracellular environments.

As is the case for mt-cpYFP, HyPer and its mutants are $\mathrm{pH}$ sensitive: a shift of $0.2 \mathrm{pH}$ units is sufficient to change the F500/F420 ratio as much as those corresponding to a full reduction or oxidation [66]. Thus, monitoring $\mathrm{pH}$ changes should be included as an essential control in HyPer measurement. A second concern is about its ROS selectivity. Although in vitro data have shown that HyPer is insensitive to other oxidants including $\mathrm{O}_{2}{ }^{--}$, GSSG, nitric oxide, and $\mathrm{ONOO}^{-}$[66], events similar to mt-cpYFP flashes were detected with mitochondrial targeted HyPer, accompanying a simultaneous stepwise increase of mitoSOX fluorescence [86]. SypHer, a pH indicator and insensitive to $\mathrm{H}_{2} \mathrm{O}_{2}$ (by a disruption of the $\mathrm{H}_{2} \mathrm{O}_{2}$-sensing cysteine pair (C199S), of HyPer), detects similar mitochondrial flash events [66, 86, 98]. Thus, since HyPer and SypHer comprise a cpYFP as the fluorophore, it is possible that the cpYFP part in these two indicators reports mitochondrial superoxide flashes [86], as do mt-cpYFP and pericam $[67,78]$.

Imaging redox potential with roGFPs

As an example of rational design, roGFP1 have been generated by substituting two surface exposed amino acids in GFP with cysteines (S147C and Q204C). The introduced Cys 147 and 204 are situated next to each other on two adjacent $\beta$ strands and form disulfide bonds due to significant conformational changes of roGFP1 upon oxidation [64, 65]. These cysteines are located near the chromophore of GFP and the formation of the disulfide bond leads to a simultaneous shift of the absorption properties. The roGFPs have two fluorescence excitation maxima at about 400 and $490 \mathrm{~nm}$, corresponding to the neutral fluorophore and anionic form of the flurophore, respectively $[64,65]$. The disulfide formation promotes protonation of the chromophore and increases the excitation peak near $400 \mathrm{~nm}$ at the expense of the peak near $490 \mathrm{~nm}$. Therefore, they serve as dual-excitation ratiometric indicators for $E_{h}$ measurement in vitro and in vivo [64, 65]. The first generation of roGFPs with different mutation sites, including roGFP1-6, all have midpoint $E_{h}$ of $-272 \mathrm{mV}$ or below, which made them most useful in reducing compartments, such as the cytosol and the mitochondrial matrix [64]. In particular, roGFP1and roGFP2 expressed in cytoplasm report a basal $E_{h}$ of -315 to $-325 \mathrm{mV}$ and both respond to a variety of oxidant stimuli [65]. Interestingly, the mitochondrial matrix of HeLa cell is highly reducing with a midpoint $E_{h}$ near $-360 \mathrm{mV}$ as reported by roGFP1; membrane-permeable reductants and oxidants reversibly change the $E_{h}$ in the matrix of mitochondria [64]. Recently, transgenic animals of roGFPs have been developed and provided very useful tools for investigating the physiology and pathology of ROS signaling [73, 99]. A combined approach using transgenic mice with mitochondrial-targeted roGFP and two-photon laser scanning microscopic imaging in brain slices have shown that normal autonomous pace-making produced oxidative stress specific to dopaminergic neurons in substantia nigra pars compacta that are usually vulnerable[73]. In mitochondrial-targeted roGFP2 transgenic Drosophilae, it has been demonstrated that elevated ROS contribute to pathogenesis in a neurodegenerative mutant ATPalpha ${ }^{D T S 1}$ and in a model of mitochondrial encephalomyopathy [99].

It should be cautioned that it takes minutes or longer for current roGFPs to equilibrate with the environmental redox potential changes and their reversibility is too slow to detect transient ROS events [32]. Indeed, roGFP2 expressed in either cytoplasm or the plasma membrane showed no response to stimulation with epidermal growth factor or lysophosphatidic acid, which induces $\mathrm{H}_{2} \mathrm{O}_{2}$ production that can be detected by DCFH $[65,100,101]$. By measuring the steady-state redox levels in different cellular compartments, future investigations may exploit roGFPs to complement the measurements using selective, fast responding, and reversible ROS indicators. Importantly, to meet the needs of measuring $E_{h}$ in severe oxidative stresses, it would also be desirable to obtain a collection of redox indicators with different midpoint potentials.

Fluorescence resonance energy transfer-based ROS indicators

Fluorescence resonance energy transfer (FRET)-based ROS indicators, which consist of cyan and yellow fluorescent proteins (CFP/YFP) linked by redox sensitive polypeptides, have also been developed. The FRET-based ROS indicators sense the redox state via their internal disulfide bonds, resulting in a conformation change of the protein leading to 
a FRET response. In this regard, Kolossov et al. developed a series of FRET ROS indicators with different redox sensitive linkers, which consist of $\alpha$-helical structures in conjunction with redox-sensitive motifs, between CFP and YFP and found that RL5 exhibited a $29 \%$ increase of FRET efficiency from its reduced to oxidized states [102]. Guzy et al. have developed a FRET ROS sensor with the 69 amino acid cysteine-containing regulatory domain from redoxregulated heat-shock protein HSP-33 [103] as the linker of CFP and YFP [104]. With this FRET indicator, they found that hypoxia-induced ROS production requires a functional mitochondrial ETC and that is essential for hypoxia-induced HIF-1 $\alpha$ stabilization [104]. A third type of FRET indicators, Redoxfluor, comprises a tandem repeat of partial sequence of carboxy-terminal cysteine-rich domain of Yap1, a yeast transcriptional factor sensing the intracellular redox state [105]. By expressing Redoxfluor to the peroxisome of yeast and Chinese hamster ovary cells, Yano et al. have demonstrated that the redox state within the peroxisomes is more reductive than that in the cytosol in wild-type cells, despite the fact that ROS are generated within the peroxisomes, and the cytosolic redox state of the of cell mutants for peroxisome assembly is more reductive than that of the wild-type cells [105]. Because FRET based-ROS measurement builds on disulfide bond formation of the redox-sensitive linkers, its specificity and kinetics are subjected to the same constraints for other disulfide bond-based ROS indicators discussed above.

\section{Perspectives}

The past decade has witnessed significant progress in understanding physiological and pathological functions of ROS, marked by the emergence of a revolutionary concept that ROS acts as cellular messengers that permeate pivotal pathways in the network of intracellular signal transduction. This ongoing revolution has been catalyzed, to a significant extent, by the advent of new small-molecule and fluorescent proteinbased ROS indicators and novel imaging methods, both conferring the ability to visualize and quantify ROS in organelle, intact cells, whole tissues and organs, and even live animals (Fig. 2). We begin to appreciate that, analogous to $\mathrm{Ca}^{2+}$ signaling, spatiotemporal ROS dynamics exhibit an exquisite hierarchical architecture in intact cells and organisms, from superoxide flashes as elemental mitochondrial ROS signaling events to cell-wide ROS oscillations [17, 106, 107] supported by the ROS-induced ROS release mechanism [39, 108] and to tissue-level ROS gradients for wound healing.

Imaging ROS in situ and in vivo, with high selectivity, quantitative ability, and spatiotemporal resolution will continue to be our most delicate investigative tool for the analysis of the tremendous complexity and subtlety of ROS signaling. To further sharpen the tool, it calls for continued efforts in designing small-molecule fluorescent ROS probes with improved selectivity, reversible kinetics and compartment-targeting property. Meanwhile, biologically inspired novel ROS indicators could be developed as we identify more ROS target proteins and understand better the mechanisms hereby they achieve signaling specificity, sensitivity and reversibility at once. Combined, the promise is that, by searching the enormous chemical space of small molecules and of proteins, we would greatly extend the current repertoire of ROS indicators and ultimately achieve the same level of reliability as we have enjoyed while measuring intracellular $\mathrm{Ca}^{2+}$ with smallmolecule probes such as fluo-3 [109], fura-2 [110], indo-1 [110], and fluorescent protein probes such as GCamp6 [111] and GECOs, the palette with blue, improved green, and or redshifted indicators [112]. In synergy with the exponentially increasing numbers of indicator-expressing organisms and disease models, the booming technology for super-resolution and single-molecule imaging [113-115], and the trend for using miniature, plant-in devices to obtain images in conscious, free-

Fig. 2 Imaging ROS dynamics

in vitro and in vivo. By combining transgenic animal models with confocal and multiphoton microscopy, images of high spatiotemporal resolution can now be acquired from isolated mitochondria, cultured cells, intact tissues or organs, and even in living animals

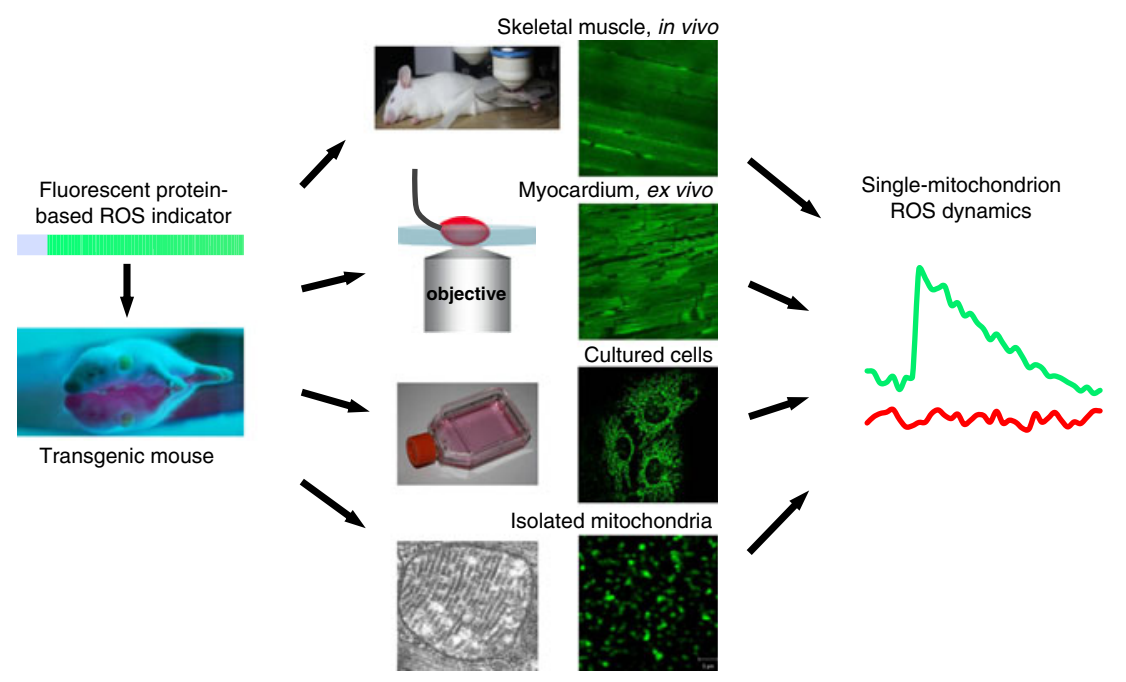


moving animals [116-120], imaging ROS in vivo will serve as the most powerful force to transform the landscape and push forward the frontiers in ROS signaling.

Acknowledgments This work was supported by the National Key Basic Research Program of China (2013CB531200 and 2011CB809100) and the National Science Foundation of China (31221002, 31130067, 31123004, and 30900264).

Open Access This article is distributed under the terms of the Creative Commons Attribution License which permits any use, distribution, and reproduction in any medium, provided the original author(s) and the source are credited.

\section{References}

1. St-Pierre J, Buckingham JA, Roebuck SJ, Brand MD (2002) Topology of superoxide production from different sites in the mitochondrial electron transport chain. J Biol Chem 277:4478444790

2. Chance B, Sies H, Boveris A (1979) Hydroperoxide metabolism in mammalian organs. Physiol Rev 59:527-605

3. Droge W (2002) Free radicals in the physiological control of cell function. Physiol Rev 82:47-95

4. Bashan N, Kovsan J, Kachko I, Ovadia H, Rudich A (2009) Positive and negative regulation of insulin signaling by reactive oxygen and nitrogen species. Physiol Rev 89:27-71

5. Turrens JF (2003) Mitochondrial formation of reactive oxygen species. J Physiol 552:335-344

6. Freinbichler W, Colivicchi MA, Stefanini C, Bianchi L, Ballini C, Misini B, Weinberger P, Linert W, Vareslija D, Tipton KF et al (2011) Highly reactive oxygen species: detection, formation, and possible functions. Cell Mol Life Sci 68:2067-2079

7. Halliwell B (2001) Role of free radicals in the neurodegenerative diseases: therapeutic implications for antioxidant treatment. Drugs Aging 18:685-716

8. Moskovitz J, Yim MB, Chock PB (2002) Free radicals and disease. Arch Biochem Biophys 397:354-359

9. Pace GW, Leaf CD (1995) The role of oxidative stress in HIV disease. Free Radic Biol Med 19:523-528

10. Berlett BS, Stadtman ER (1997) Protein oxidation in aging, disease, and oxidative stress. J Biol Chem 272:20313-20316

11. Valko M, Leibfritz D, Moncol J, Cronin MT, Mazur M, Telser J (2007) Free radicals and antioxidants in normal physiological functions and human disease. Int J Biochem Cell Biol 39:44-84

12. Newsholme P, Haber EP, Hirabara SM, Rebelato EL, Procopio J, Morgan D, Oliveira-Emilio HC, Carpinelli AR, Curi R (2007) Diabetes associated cell stress and dysfunction: role of mitochondrial and non-mitochondrial ROS production and activity. J Physiol 583:9-24

13. Chinta SJ, Andersen JK (2008) Redox imbalance in Parkinson's disease. Biochim Biophys Acta 1780:1362-1367

14. Wells PG, McCallum GP, Chen CS, Henderson JT, Lee CJ, Perstin J, Preston TJ, Wiley MJ, Wong AW (2009) Oxidative stress in developmental origins of disease: teratogenesis, neurodevelopmental deficits, and cancer. Toxicol Sci 108:4-18

15. Harman D (2006) Free radical theory of aging: an update: increasing the functional life span. Ann N Y Acad Sci 1067:10-21

16. Beckman KB, Ames BN (1998) The free radical theory of aging matures. Physiol Rev 78:547-581

17. Yan Y, Liu J, Wei C, Li K, Xie W, Wang Y, Cheng H (2008) Bidirectional regulation of $\mathrm{Ca} 2+$ sparks by mitochondria-derived reactive oxygen species in cardiac myocytes. Cardiovasc Res $77: 432-441$
18. Zhao Z, Wen H, Fefelova N, Allen C, Baba A, Matsuda T, Xie LH (2012) Revisiting the ionic mechanisms of early afterdepolarizations in cardiomyocytes: predominant by Ca waves or Ca currents? Am J Physiol Heart Circ Physiol 302:H1636-H1644

19. Dimmeler S, Zeiher AM (2007) A "reductionist" view of cardiomyopathy. Cell 130:401-402

20. Rajasekaran NS, Connell P, Christians ES, Yan LJ, Taylor RP, Orosz A, Zhang XQ, Stevenson TJ, Peshock RM, Leopold JA et al (2007) Human alpha B-crystallin mutation causes oxido-reductive stress and protein aggregation cardiomyopathy in mice. Cell 130:427-439

21. Owusu-Ansah E, Banerjee U (2009) Reactive oxygen species prime Drosophila haematopoietic progenitors for differentiation. Nature 461:537-541

22. Maryanovich M, Gross A (2013) A ROS rheostat for cell fate regulation. Trends Cell Biol 23(3):129-134

23. Hou Y, Ouyang X, Wan R, Cheng H, Mattson MP, Cheng A (2012) Mitochondrial superoxide production negatively regulates neural progenitor proliferation and cerebral cortical development. Stem Cells 30:2535-2547

24. Adler V, Yin Z, Tew KD, Ronai Z (1999) Role of redox potential and reactive oxygen species in stress signaling. Oncogene 18:6104-6111

25. Niethammer P, Grabher C, Look AT, Mitchison TJ (2009) A tissue-scale gradient of hydrogen peroxide mediates rapid wound detection in zebrafish. Nature 459:996-999

26. Yoo SK, Starnes TW, Deng Q, Huttenlocher A (2011) Lyn is a redox sensor that mediates leukocyte wound attraction in vivo. Nature 480:109-112

27. Giordano FJ (2005) Oxygen, oxidative stress, hypoxia, and heart failure. J Clin Invest 115:500-508

28. Marchioli R, Schweiger C, Levantesi G, Tavazzi L, Valagussa F (2001) Antioxidant vitamins and prevention of cardiovascular disease: epidemiological and clinical trial data. Lipids 36(Suppl):S53S63

29. El-Hamamsy I, Stevens LM, Carrier M, Pellerin M, Bouchard D, Demers P, Cartier R, Page P, Perrault LP (2007) Effect of intravenous $N$-acetylcysteine on outcomes after coronary artery bypass surgery: a randomized, double-blind, placebo-controlled clinical trial. J Thorac Cardiovasc Surg 133:7-12

30. Chae CU, Albert CM, Moorthy MV, Lee IM, Buring JE (2012) Vitamin E supplementation and the risk of heart failure in women. Circ Heart Fail 5:176-182

31. Rhee SG, Chang TS, Jeong W, Kang D (2010) Methods for detection and measurement of hydrogen peroxide inside and outside of cells. Mol Cells 29:539-549

32. Meyer AJ, Dick TP (2010) Fluorescent protein-based redox probes. Antioxid Redox Signal 13:621-650

33. Kalyanaraman B, Darley-Usmar V, Davies KJ, Dennery PA, Forman HJ, Grisham MB, Mann GE, Moore K, Roberts LJ 2nd, Ischiropoulos H (2012) Measuring reactive oxygen and nitrogen species with fluorescent probes: challenges and limitations. Free Radic Biol Med 52:1-6

34. Forkink M, Smeitink JA, Brock R, Willems PH, Koopman WJ (2010) Detection and manipulation of mitochondrial reactive oxygen species in mammalian cells. Biochim Biophys Acta 1797:1034-1044

35. Dikalov SI, Harrison DG (2012) Methods for detection of mitochondrial and cellular reactive oxygen species. Antioxid Redox Signal. doi:10.1089/ars.2012.4886

36. Hempel SL, Buettner GR, O’Malley YQ, Wessels DA, Flaherty DM (1999) Dihydrofluorescein diacetate is superior for detecting intracellular oxidants: comparison with $2^{\prime}, 7^{\prime}$-dichlorodihydrofluorescein diacetate, 5(and 6)-carboxy-2',7'-dichlorodihydrofluorescein diacetate, and dihydrorhodamine 123 . Free Radic Biol Med 27:146-159

37. Prosser BL, Ward CW, Lederer WJ (2011) X-ROS signaling: rapid mechano-chemo transduction in heart. Science 333:1440-1445 
38. Curtin JF, Donovan M, Cotter TG (2002) Regulation and measurement of oxidative stress in apoptosis. J Immunol Methods 265:49-72

39. Zorov DB, Filburn CR, Klotz LO, Zweier JL, Sollott SJ (2000) Reactive oxygen species (ROS)-induced ROS release: a new phenomenon accompanying induction of the mitochondrial permeability transition in cardiac myocytes. J Exp Med 192:10011014

40. Zhao H, Kalivendi S, Zhang H, Joseph J, Nithipatikom K, Vasquez-Vivar J, Kalyanaraman B (2003) Superoxide reacts with hydroethidine but forms a fluorescent product that is distinctly different from ethidium: potential implications in intracellular fluorescence detection of superoxide. Free Radic Biol Med 34:1359-1368

41. Zhao H, Joseph J, Fales HM, Sokoloski EA, Levine RL, VasquezVivar J, Kalyanaraman B (2005) Detection and characterization of the product of hydroethidine and intracellular superoxide by HPLC and limitations of fluorescence. Proc Natl Acad Sci U S A 102:5727-5732

42. Zielonka J, Srinivasan S, Hardy M, Ouari O, Lopez M, VasquezVivar J, Avadhani NG, Kalyanaraman B (2008) Cytochrome cmediated oxidation of hydroethidine and mito-hydroethidine in mitochondria: identification of homo- and heterodimers. Free Radic Biol Med 44:835-846

43. Zielonka J, Kalyanaraman B (2010) Hydroethidine- and MitoSOX-derived red fluorescence is not a reliable indicator of intracellular superoxide formation: another inconvenient truth. Free Radic Biol Med 48:983-1001

44. Robinson KM, Janes MS, Beckman JS (2008) The selective detection of mitochondrial superoxide by live cell imaging. Nat Protoc 3:941-947

45. Dikalov S, Griendling KK, Harrison DG (2007) Measurement of reactive oxygen species in cardiovascular studies. Hypertension 49:717-727

46. Zielonka J, Sarna T, Roberts JE, Wishart JF, Kalyanaraman B (2006) Pulse radiolysis and steady-state analyses of the reaction between hydroethidine and superoxide and other oxidants. Arch Biochem Biophys 456:39-47

47. Fernandes DC, Wosniak J Jr, Pescatore LA, Bertoline MA, Liberman M, Laurindo FR, Santos CX (2007) Analysis of DHEderived oxidation products by HPLC in the assessment of superoxide production and NADPH oxidase activity in vascular systems. Am J Physiol Cell Physiol 292:C413-C422

48. Meany DL, Thompson L, Arriaga EA (2007) Simultaneously monitoring the superoxide in the mitochondrial matrix and extramitochondrial space by micellar electrokinetic chromatography with laser-induced fluorescence. Anal Chem 79:4588-4594

49. Robinson KM, Janes MS, Pehar M, Monette JS, Ross MF, Hagen TM, Murphy MP, Beckman JS (2006) Selective fluorescent imaging of superoxide in vivo using ethidium-based probes. Proc Natl Acad Sci U S A 103:15038-15043

50. Zielonka J, Vasquez-Vivar J, Kalyanaraman B (2008) Detection of 2-hydroxyethidium in cellular systems: a unique marker product of superoxide and hydroethidine. Nat Protoc 3:8-21

51. Porwol T, Ehleben W, Zierold K, Fandrey J, Acker H (1998) The influence of nickel and cobalt on putative members of the oxygensensing pathway of erythropoietin-producing HepG2 cells. Eur J Biochem 256:16-23

52. Wardman P (2007) Fluorescent and luminescent probes for measurement of oxidative and nitrosative species in cells and tissues: progress, pitfalls, and prospects. Free Radic Biol Med 43:995-1022

53. Crow JP (1997) Dichlorodihydrofluorescein and dihydrorhodamine 123 are sensitive indicators of peroxynitrite in vitro: implications for intracellular measurement of reactive nitrogen and oxygen species. Nitric Oxide 1:145-157

54. Royall JA, Ischiropoulos H (1993) Evaluation of 2',7'dichlorofluorescin and dihydrorhodamine 123 as fluorescent probes for intracellular $\mathrm{H} 2 \mathrm{O} 2$ in cultured endothelial cells. Arch Biochem Biophys 302:348-355

55. Chang MC, Pralle A, Isacoff EY, Chang CJ (2004) A selective, cell-permeable optical probe for hydrogen peroxide in living cells. J Am Chem Soc 126:15392-15393

56. Miller EW, Albers AE, Pralle A, Isacoff EY, Chang CJ (2005) Boronate-based fluorescent probes for imaging cellular hydrogen peroxide. J Am Chem Soc 127:16652-16659

57. Dickinson BC, Chang CJ (2008) A targetable fluorescent probe for imaging hydrogen peroxide in the mitochondria of living cells. J Am Chem Soc 130:9638-9639

58. Sikora A, Zielonka J, Lopez M, Dybala-Defratyka A, Joseph J, Marcinek A, Kalyanaraman B (2011) Reaction between peroxynitrite and boronates: EPR spin-trapping, HPLC analyses, and quantum mechanical study of the free radical pathway. Chem Res Toxicol 24:687-697

59. Zielonka J, Sikora A, Joseph J, Kalyanaraman B (2010) Peroxynitrite is the major species formed from different flux ratios of co-generated nitric oxide and superoxide: direct reaction with boronate-based fluorescent probe. J Biol Chem 285:14210-14216

60. Peng T, Yang D (2010) HKGreen-3: a rhodol-based fluorescent probe for peroxynitrite. Org Lett 12:4932-4935

61. Sun ZN, Liu FQ, Chen Y, Tam PK, Yang D (2008) A highly specific BODIPY-based fluorescent probe for the detection of hypochlorous acid. Org Lett 10:2171-2174

62. Cortese-Krott MM, Rodriguez-Mateos A, Kuhnle GG, Brown G, Feelisch M, Kelm M (2012) A multilevel analytical approach for detection and visualization of intracellular NO production and nitrosation events using diaminofluoresceins. Free Radic Biol Med 53:2146-2158

63. Nikic I, Merkler D, Sorbara C, Brinkoetter M, Kreutzfeldt M, Bareyre FM, Bruck W, Bishop D, Misgeld T, Kerschensteiner M (2011) A reversible form of axon damage in experimental autoimmune encephalomyelitis and multiple sclerosis. Nat Med 17:495-499

64. Hanson GT, Aggeler R, Oglesbee D, Cannon M, Capaldi RA, Tsien RY, Remington SJ (2004) Investigating mitochondrial redox potential with redox-sensitive green fluorescent protein indicators. J Biol Chem 279:13044-13053

65. Dooley CT, Dore TM, Hanson GT, Jackson WC, Remington SJ, Tsien RY (2004) Imaging dynamic redox changes in mammalian cells with green fluorescent protein indicators. J Biol Chem 279:22284-22293

66. Belousov VV, Fradkov AF, Lukyanov KA, Staroverov DB, Shakhbazov KS, Terskikh AV, Lukyanov S (2006) Genetically encoded fluorescent indicator for intracellular hydrogen peroxide. Nat Methods 3:281-286

67. Wang W, Fang H, Groom L, Cheng A, Zhang W, Liu J, Wang X, Li K, Han P, Zheng M et al (2008) Superoxide flashes in single mitochondria. Cell 134:279-290

68. VanEngelenburg SB, Palmer AE (2008) Fluorescent biosensors of protein function. Curr Opin Chem Biol 12:60-65

69. Miyawaki A, Llopis J, Heim R, McCaffery JM, Adams JA, Ikura M, Tsien RY (1997) Fluorescent indicators for Ca2+ based on green fluorescent proteins and calmodulin. Nature 388:882-887

70. Fang H, Chen M, Ding Y, Shang W, Xu J, Zhang X, Zhang W, Li $\mathrm{K}$, Xiao Y, Gao F et al (2011) Imaging superoxide flash and metabolism-coupled mitochondrial permeability transition in living animals. Cell Res 21:1295-1304

71. Fang H, Zhang W, Wang X, Wang W, Li K, Wang Y, Zhang X, Shang S, Tian XL, Zhou J et al (2009) In vivo imaging of superoxide flashes in skeletal muscle. Biophys J 96:530a

72. Bilan DS, Pase L, Joosen L, Gorokhovatsky AY, Ermakova YG, Gadella TW, Grabher C, Schultz C, Lukyanov S, Belousov VV (2013) HyPer-3: a genetically encoded $\mathrm{H}(2) \mathrm{O}(2)$ probe with improved performance for ratiometric and fluorescence lifetime imaging. ACS Chem Biol 8(3):535-542 
73. Guzman JN, Sanchez-Padilla J, Wokosin D, Kondapalli J, Ilijic E, Schumacker PT, Surmeier DJ (2010) Oxidant stress evoked by pacemaking in dopaminergic neurons is attenuated by DJ-1. Nature 468:696-700

74. Nagai T, Sawano A, Park ES, Miyawaki A (2001) Circularly permuted green fluorescent proteins engineered to sense $\mathrm{Ca} 2+$. Proc Natl Acad Sci U S A 98:3197-3202

75. Wang X, Jian C, Zhang X, Huang Z, Xu J, Hou T, Shang W, Ding Y, Zhang W, Ouyang M et al (2012) Superoxide flashes: elemental events of mitochondrial ROS signaling in the heart. J Mol Cell Cardiol 52:940-948

76. Wei L, Salahura G, Boncompagni S, Kasischke KA, Protasi F, Sheu SS, Dirksen RT (2011) Mitochondrial superoxide flashes: metabolic biomarkers of skeletal muscle activity and disease. FASEB J 25:3068-3078

77. Wei L, Dirksen RT (2012) Perspectives on: SGP symposium on mitochondrial physiology and medicine: mitochondrial superoxide flashes: from discovery to new controversies. J Gen Physiol 139:425-434

78. Pouvreau S (2010) Superoxide flashes in mouse skeletal muscle are produced by discrete arrays of active mitochondria operating coherently. PLoS One. doi:10.1371/journal.pone.0013035

79. Ma Q, Fang H, Shang W, Liu L, Xu Z, Ye T, Wang X, Zheng M, Chen Q, Cheng H (2011) Superoxide flashes: early mitochondrial signals for oxidative stress-induced apoptosis. J Biol Chem 286:27573-27581

80. Li K, Zhang W, Fang H, Xie W, Liu J, Zheng M, Wang X, Wang W, Tan W, Cheng H (2012) Superoxide flashes reveal novel properties of mitochondrial reactive oxygen species excitability in cardiomyocytes. Biophys J 102:1011-1021

81. Hou T, Zhang X, Xu J, Jian C, Huang Z, Ye T, Hu K, Zheng M, Gao F, Wang X et al (2013) Synergistic triggering of superoxide flashes by mitochondrial $\mathrm{Ca} 2+$ uniport and basal reactive oxygen species elevation. J Biol Chem 288:4602-4612

82. Wang JQ, Chen Q, Wang X, Wang QC, Wang Y, Cheng HP, Guo C, Sun Q, Tang TS (2013) Dysregulation of mitochondrial calcium signaling and superoxide flashes cause mitochondrial genomic DNA damage in Huntington disease. J Biol Chem 288:3070-3084

83. Wei-Lapierre L, Gong G, Gerstner BJ, Ducreux S, Yule DI, Pouvreau S, Wang X, Sheu SS, Cheng H, Dirksen RT et al (2013) Respective contribution of mitochondrial superoxide and pH to mt-cpYFP flash activity. J Biol Chem 288:10567-10577

84. Schwarzlander M, Logan DC, Fricker MD, Sweetlove LJ (2011) The circularly permuted yellow fluorescent protein cpYFP that has been used as a superoxide probe is highly responsive to $\mathrm{pH}$ but not superoxide in mitochondria: implications for the existence of superoxide 'flashes'. Biochem J 437:381-387

85. Schwarzlander M, Murphy MP, Duchen MR, Logan DC, Fricker MD, Halestrap AP, Muller FL, Rizzuto R, Dick TP, Meyer AJ et al (2012) Mitochondrial 'flashes': a radical concept repHined. Trends Cell Biol 22:503-508

86. Quatresous E, Legrand C, Pouvreau S (2012) Mitochondria-targeted cpYFP: pH or superoxide sensor? J Gen Physiol 140:567-570

87. Nakagawa T, Shimizu S, Watanabe T, Yamaguchi O, Otsu K, Yamagata H, Inohara H, Kubo T, Tsujimoto Y (2005) Cyclophilin D-dependent mitochondrial permeability transition regulates some necrotic but not apoptotic cell death. Nature 434:652-658

88. Baines CP, Kaiser RA, Purcell NH, Blair NS, Osinska H, Hambleton MA, Brunskill EW, Sayen MR, Gottlieb RA, Dorn GW et al (2005) Loss of cyclophilin D reveals a critical role for mitochondrial permeability transition in cell death. Nature 434:658-662

89. Schinzel AC, Takeuchi O, Huang Z, Fisher JK, Zhou Z, Rubens J, Hetz C, Danial NN, Moskowitz MA, Korsmeyer SJ (2005) Cyclophilin D is a component of mitochondrial permeability transition and mediates neuronal cell death after focal cerebral ischemia. Proc Natl Acad Sci U S A 102:12005-12010
90. Basso E, Fante L, Fowlkes J, Petronilli V, Forte MA, Bernardi P (2005) Properties of the permeability transition pore in mitochondria devoid of cyclophilin D. J Biol Chem 280:18558-18561

91. Turrens JF, Alexandre A, Lehninger AL (1985) Ubisemiquinone is the electron donor for superoxide formation by complex III of heart mitochondria. Arch Biochem Biophys 237:408-414

92. Chen Q, Vazquez EJ, Moghaddas S, Hoppel CL, Lesnefsky EJ (2003) Production of reactive oxygen species by mitochondria: central role of complex III. J Biol Chem 278:36027-36031

93. Bonora M, Bononi A, De Marchi E, Giorgi C, Lebiedzinska M, Marchi S, Patergnani S, Rimessi A, Suski JM, Wojtala A et al (2013) Role of the c subunit of the FO ATP synthase in mitochondrial permeability transition. Cell Cycle 12:674-683

94. Giorgio V, von Stockum S, Antoniel M, Fabbro A, Fogolari F, Forte M, Glick GD, Petronilli V, Zoratti M, Szabo I et al (2013) Dimers of mitochondrial ATP synthase form the permeability transition pore. Proc Natl Acad Sci U S A 110(15):5887-5892

95. Huang Z, Zhang W, Gong G, Fang H, Zheng M, Wang X, Xu J, Dirksen RT, Sheu SS, Cheng H et al (2011) Response to "A critical evaluation of cpYFP as a probe for superoxide". Free Radic Biol Med $51: 1937-1940$

96. Espinosa A, Garcia A, Hartel S, Hidalgo C, Jaimovich E (2009) NADPH oxidase and hydrogen peroxide mediate insulin-induced calcium increase in skeletal muscle cells. J Biol Chem 284:25682575

97. Markvicheva KN, Bilan DS, Mishina NM, Gorokhovatsky AY, Vinokurov LM, Lukyanov S, Belousov VV (2011) A genetically encoded sensor for $\mathrm{H} 2 \mathrm{O} 2$ with expanded dynamic range. Bioorg Med Chem 19:1079-1084

98. Poburko D, Santo-Domingo J, Demaurex N (2011) Dynamic regulation of the mitochondrial proton gradient during cytosolic calcium elevations. J Biol Chem 286:11672-11684

99. Liu Z, Celotto AM, Romero G, Wipf P, Palladino MJ (2012) Genetically encoded redox sensor identifies the role of ROS in degenerative and mitochondrial disease pathogenesis. Neurobiol Dis 45:362-368

100. Bae YS, Kang SW, Seo MS, Baines IC, Tekle E, Chock PB, Rhee SG (1997) Epidermal growth factor (EGF)-induced generation of hydrogen peroxide. Role in EGF receptor-mediated tyrosine phosphorylation. J Biol Chem 272:217-221

101. Sekharam M, Cunnick JM, Wu J (2000) Involvement of lipoxygenase in lysophosphatidic acid-stimulated hydrogen peroxide release in human HaCaT keratinocytes. Biochem J 346(Pt 3):751-758

102. Kolossov VL, Spring BQ, Sokolowski A, Conour JE, Clegg RM, Kenis PJ, Gaskins HR (2008) Engineering redox-sensitive linkers for genetically encoded FRET-based biosensors. Exp Biol Med (Maywood) 233:238-248

103. Jakob U, Muse W, Eser M, Bardwell JC (1999) Chaperone activity with a redox switch. Cell 96:341-352

104. Guzy RD, Hoyos B, Robin E, Chen H, Liu L, Mansfield KD, Simon MC, Hammerling U, Schumacker PT (2005) Mitochondrial complex III is required for hypoxia-induced ROS production and cellular oxygen sensing. Cell Metab 1:401-408

105. Yano T, Oku M, Akeyama N, Itoyama A, Yurimoto H, Kuge S, Fujiki Y, Sakai Y (2010) A novel fluorescent sensor protein for visualization of redox states in the cytoplasm and in peroxisomes. Mol Cell Biol 30:3758-3766

106. Aon MA, Cortassa S, Marban E, O’Rourke B (2003) Synchronized whole cell oscillations in mitochondrial metabolism triggered by a local release of reactive oxygen species in cardiac myocytes. J Biol Chem 278:44735-44744

107. Aon MA, Cortassa S, O’Rourke B (2008) Mitochondrial oscillations in physiology and pathophysiology. Adv Exp Med Biol 641:98-117

108. Zorov DB, Juhaszova M, Sollott SJ (2006) Mitochondrial ROSinduced ROS release: an update and review. Biochim Biophys Acta 1757:509-517 
109. Minta A, Kao JP, Tsien RY (1989) Fluorescent indicators for cytosolic calcium based on rhodamine and fluorescein chromophores. J Biol Chem 264:8171-8178

110. Grynkiewicz G, Poenie M, Tsien RY (1985) A new generation of $\mathrm{Ca} 2+$ indicators with greatly improved fluorescence properties. J Biol Chem 260:3440-3450

111. Ohkura M, Sasaki T, Sadakari J, Gengyo-Ando K, KagawaNagamura Y, Kobayashi C, Ikegaya Y, Nakai J (2012) Genetically encoded green fluorescent $\mathrm{Ca} 2+$ indicators with improved detectability for neuronal $\mathrm{Ca} 2+$ signals. PLoS One 7:e51286

112. Zhao Y, Araki S, Wu J, Teramoto T, Chang YF, Nakano M, Abdelfattah AS, Fujiwara M, Ishihara T, Nagai T et al (2011) An expanded palette of genetically encoded $\mathrm{Ca}(2)(+)$ indicators. Science 333:1888-1891

113. Rust MJ, Bates M, Zhuang X (2006) Sub-diffraction-limit imaging by stochastic optical reconstruction microscopy (STORM). Nat Methods 3:793-795

114. Betzig E, Patterson GH, Sougrat R, Lindwasser OW, Olenych S, Bonifacino JS, Davidson MW, Lippincott-Schwartz J, Hess HF
(2006) Imaging intracellular fluorescent proteins at nanometer resolution. Science 313:1642-1645

115. Westphal V, Rizzoli SO, Lauterbach MA, Kamin D, Jahn R, Hell SW (2008) Video-rate far-field optical nanoscopy dissects synaptic vesicle movement. Science 320:246-249

116. Rector D, Harper R (1991) Imaging of hippocampal neural activity in freely behaving animals. Behav Brain Res 42:143-149

117. Gobel W, Kerr JN, Nimmerjahn A, Helmchen F (2004) Miniaturized two-photon microscope based on a flexible coherent fiber bundle and a gradient-index lens objective. Opt Lett 29:2521-2523

118. Flusberg BA, Cocker ED, Piyawattanametha W, Jung JC, Cheung EL, Schnitzer MJ (2005) Fiber-optic fluorescence imaging. Nat Methods 2:941-950

119. Pillai RS, Lorenser D, Sampson DD (2011) Deep-tissue access with confocal fluorescence microendoscopy through hypodermic needles. Opt Express 19:7213-7221

120. Piyawattanametha W, Cocker ED, Burns LD, Barretto RP, Jung JC, Ra $\mathrm{H}$, Solgaard O, Schnitzer MJ (2009) In vivo brain imaging using a portable $2.9 \mathrm{~g}$ two-photon microscope based on a microelectromechanical systems scanning mirror. Opt Lett 34:2309-2311 